\title{
Article \\ Using Energy Storage Inverters of Prosumer Installations for Voltage Control in Low-Voltage Distribution Networks
}

\author{
Rozmysław Mieński, Przemysław Urbanek*(D) and Irena Wasiak \\ Institute of Electrical Power Engineering, Lodz University of Technology, 90924 Łódź, Poland; \\ rozmyslaw.mienski@p.lodz.pl (R.M.); irena.wasiak@p.lodz.pl (I.W.) \\ * Correspondence: przemyslaw.urbanek@dokt.p.lodz.pl; Tel.: +48-604-170-594
}

check for

updates

Citation: Mieński, R.; Urbanek, P.; Wasiak, I. Using Energy Storage Inverters of Prosumer Installations for Voltage Control in Low-Voltage Distribution Networks. Energies 2021, 14, 1121. https://doi.org/10.3390/ en14041121

Received: 13 January 2021

Accepted: 16 February 2021

Published: 20 February 2021

Publisher's Note: MDPI stays neutral with regard to jurisdictional claims in published maps and institutional affiliations.

Copyright: (c) 2021 by the authors. Licensee MDPI, Basel, Switzerland. This article is an open access article distributed under the terms and conditions of the Creative Commons Attribution (CC BY) license (https:/ / creativecommons.org/licenses/by/ $4.0 /)$.

\begin{abstract}
The paper includes the analysis of the operation of low-voltage prosumer installation consisting of receivers and electricity sources and equipped with a 3-phase energy storage system. The aim of the storage application is the management of active power within the installation to decrease the total power exchanged with the supplying network and thus reduce energy costs borne by the prosumer. A solution for the effective implementation of the storage system is presented. Apart from the active power management performed according to the prosumer's needs, the storage inverter provides the ancillary service of voltage regulation in the network according to the requirements of the network operator. A control strategy involving algorithms for voltage regulation without prejudice to the prosumer's interest is described in the paper. Reactive power is used first as a control signal and if the required voltage effect cannot be reached, then the active power in the controlled phase is additionally changed and the Energy Storage System (ESS) loading is redistributed in phases in such a way that the total active power set by the prosumer program remains unchanged. The efficiency of the control strategy was tested by means of a simulation model in the PSCAD/EMTDC program. The results of the simulations are presented.
\end{abstract}

Keywords: voltage regulation in a low-voltage network; prosumer installation; energy storage; energy management; ancillary services

\section{Introduction}

The development of energy-generating technologies and the introduction of government programs for subsidizing renewable energy sources (RESs) together with attempts to increase energy efficiency resulted in a growing interest among customers in having their own power plants. As a consequence, a continuous increase in the number of households in which RESs have been installed is observed and the structure and operating conditions of the low-voltage (LV) distribution networks have been changing gradually [1-6].

The most typical sources in prosumer installations are photovoltaic panels (PVs) [2,7-11] using free solar energy. Randomly varying and nondispatchable power generated by such sources may result in voltage variations, unacceptable voltage rise in the network nodes and uncontrolled power flows in the network. Moreover, voltage unbalance may appear due to the fact that PV sources are in many cases single-phase. These phenomena cause the deterioration of power quality in the network and, when negative impacts of many prosumer installations are accumulated, lead to disruptions in the network operation [12]. It should be emphasised that the consequences of poor power quality are borne by all customers supplied from the network. Under such conditions, the maintenance of proper network operation with the required power quality (PQ) indices may become a problem for the network operator and may require that control measures be introduced. Past experience has shown that overvoltage is a major problem [13-18].

The possibilities of direct voltage regulation in most existing LV distribution networks are limited and usually involve a gradual change in the voltage transformation ratio of 
distribution transformers using transformer tap changers. As distribution transformers are usually equipped with off-load tap-changers, online voltage control is not possible. Voltage regulation is performed periodically after disconnecting a transformer from the network.

The well-known methods of indirect voltage regulation involve the changing of power flow in the network. Active and reactive power flowing through the network branches results in a voltage drop on the network impedance and, as a consequence, affects the voltage level in network nodes. Typical regulation concerns the use of reactive power which gives the $Q X / U$ voltage drop component on the network reactance.

Proposals for indirect voltage regulation involving devices located in prosumer installations can be found in literature. Publications [19,20] show using PV inverters to change the reactive power introduced to the network to mitigate the voltage increase at the point of common coupling (PCC). The reactive power value is dependent on the active power generated by the PV source and limited by total current carrying capacity of the PV inverter. In practice, PV inverters operate usually with $\cos \varphi=1$, so their use for voltage regulation by changing the reactive power flow in the network is relatively small.

In [21,22] a similar way of the overvoltage reduction caused by PV generation, by using energy storage systems (ESSs) located in a prosumer installation, has been presented.

It should be noted that voltage regulation only by changing reactive power flow is appropriate as long as the $\mathrm{X} / \mathrm{R}$ ratio of the network impedance is relatively high. That is not the case for LV networks where voltage drop is affected more by active power flow.

Examples of voltage regulation by means of active power can be found in literature. Article [23] shows the use of controllable inverters that in the first stage of regulation draw reactive power from the network in order to increase the voltage drop, and if this is ineffective, in the second stage reduce the generation of active power. Another solution to reduce overvoltage at the PCC is presented in [24], where the PV source in a prosumer installation cooperates with an ESS. If the limit voltage is exceeded at the PCC, the ESS is charged with a specific power, which results in a decrease of the active power transmitted to the network and at the same time a decrease in the voltage value. It should be noted that in such systems, PV inverters are prevented from disconnection caused by excessive voltage increases due to overvoltages, contributing to an increase in the reliability of PV systems operation.

The option of voltage regulation by changing the active power flow using ESSs may be applied to distribution networks. Article [25] shows regulation possibilities obtained by installing ESSs in network nodes together with a central control system which detects voltage excess beyond limit values, based on which ESSs are charging and discharging. In the presented proposal, ESSs are only used for regulation purposes. Functions such as active power management for the optimisation of the network operation are omitted.

A similar way of regulation is presented in [26], where several functionalities, i.e., voltage regulation, the management of active power and cost optimization in the network, have been implemented for all electric energy storage tanks in the prosumer installation. The above functionalities are implemented by means of active and reactive power generation/consumption in order of priority. The provision of regulation service interferes with other functionalities.

In [27], a proposal to support the power network operation by making prosumer installation ESS infrastructure available for ancillary services is submitted. The prosumer's local control focuses on the ESS back-up power supply and island operation as well as primary frequency control if deviations are detected locally. The network operator, according to its own criteria, issues commands to the installation in order to realize a specific service, i.e., network balancing, network voltage regulation, active power management. These ancillary services have a higher priority; thus, the local control is interfered with by the operation of energy storage facilities for the operator.

Publication [28] presents a single installation with a PV and an ESS which, according to the commands from the central controller, performs active power management by 
regulating the value of power exchanged with the grid and the local compensation of higher harmonics.

Voltage regulation by means of an EV storage system in a prosumer installation consisting of PV and wind generator systems is proposed in [29]. This publication presents the effects of active and reactive power changes in local, central and combined control. The issue of cost management in the prosumer installation is not raised.

The possibility of regulating power flow in the network by means of ESSs in prosumers' installations is beneficial for the network operator because it may help in maintaining the required power quality or minimizing active power losses in the network. However, a prosumer will be more interested in the application of the ESS for his own purposes. Typically, ESS in a prosumer installation manages active power by storing surplus energy generated by the PV panels during the periods of low power demand and releasing it when the local demand is high. In doing so, the storage system becomes a power and energy buffer, reducing the cost of purchasing energy from the network for the prosumer. Energy storage devices can similarly benefit all customer installations, even without energy sources, following a defined schedule of charging and discharging.

Literature presents various ways of optimizing electricity flows in prosumer installations to increase savings [30-48]. Varying by country in legal regulations for financial arrangements between the prosumer and the operator, all methods are characterized by minimising the parameter which is responsible for costs, i.e., 3-phase energy value.

It seems obvious that using the ESS for performing the regulation service for the network operator is only attractive for the prosumer when this service does not interfere with the ESS basic application or if appropriate regulations and financial incentives exist. To the authors' knowledge, there are currently no such systems or control strategies dedicated to the ESSs in prosumer installations that would combine active power management with voltage regulation performed as an ancillary service for the network operator, at the same time ensuring profit for the prosumer. This gap is addressed in this paper.

This paper presents a new method for an effective utilization of 3-phase ESS inverters in prosumer installations. A strategy for active power management is proposed, according to which the 3-phase active power schedule (ESS charging and discharging pattern) is determined. A voltage regulation algorithm is incorporated into the strategy, allowing the voltage at the PCC to be maintained according to the requirements of the network operator or the set values imposed by an external control system. The regulation is performed in individual phases.

It is assumed that reactive power takes priority for regulation purposes. Only if the required voltage effect cannot be reached by means of reactive power due to the limited inverter capacity, then the active power in the controlled phase is additionally changed to a value resulting in the expected voltage regulation effect. The novelty of the method is that at the same time the ESS active power load is redistributed in phases in such a way that the total 3-phase active power does not change.

The solution minimizes the use of active power for regulation purposes and compensates for the disruption of local prosumer program, i.e., the ESS inverter additional service does not interfere with its basic task. This feature of the method is important for the prosumer who is to participate in the network ancillary services.

The paper is arranged as follows: in Section 2, the strategies for active power and energy management applied in prosumer installations for energy storage systems are described; then, in Section 3, the proposed method of the ESS inverter control for voltage regulation is presented and evaluated in a simple test system; Section 4 contains the results of simulations illustrating the ESS operation in a prosumer installation and its participation in a voltage regulation service; the last section includes conclusions. 


\section{Active Power Management in Prosumer Installations}

\subsection{Management Strategies}

Due to different definitions and legal regulations concerning prosumers [49,50], the strategies of power management in prosumer installations may vary by location and depend on the billing principles for prosumers. In Poland, these principles are regulated by [51] and are based on a system of discounts.

According to law regulations [51], a prosumer is the final customer purchasing electricity on the basis of a comprehensive agreement with the network operator and generating electricity exclusively from renewable energy sources in a micro installation for his own use, not related to his business activity. The prosumer is billed for the consumption of electricity as an ordinary customer, while the energy generated from own source reduces their energy consumption from the power grid. Any energy that cannot be balanced locally is introduced to the grid and settled in the form of discounts. This means that for $1 \mathrm{kWh}$ of energy introduced into the network, the prosumer may take a certain amount of energy from the network for free, e.g., for power sources not exceeding $10 \mathrm{kWp}$ this amount is $0.8 \mathrm{kWh}$. It is therefore clear that from the prosumer's point of view, transferring energy to the grid can be uneconomical, and an energy management system is needed.

Figure 1 below shows a typical prosumer installation consisting of loads and a PV system in a single-family house. For a better utilization of energy generated locally by the PV source and thereby increasing savings from the reduction of the network power consumption, an ESS is added to the installation.

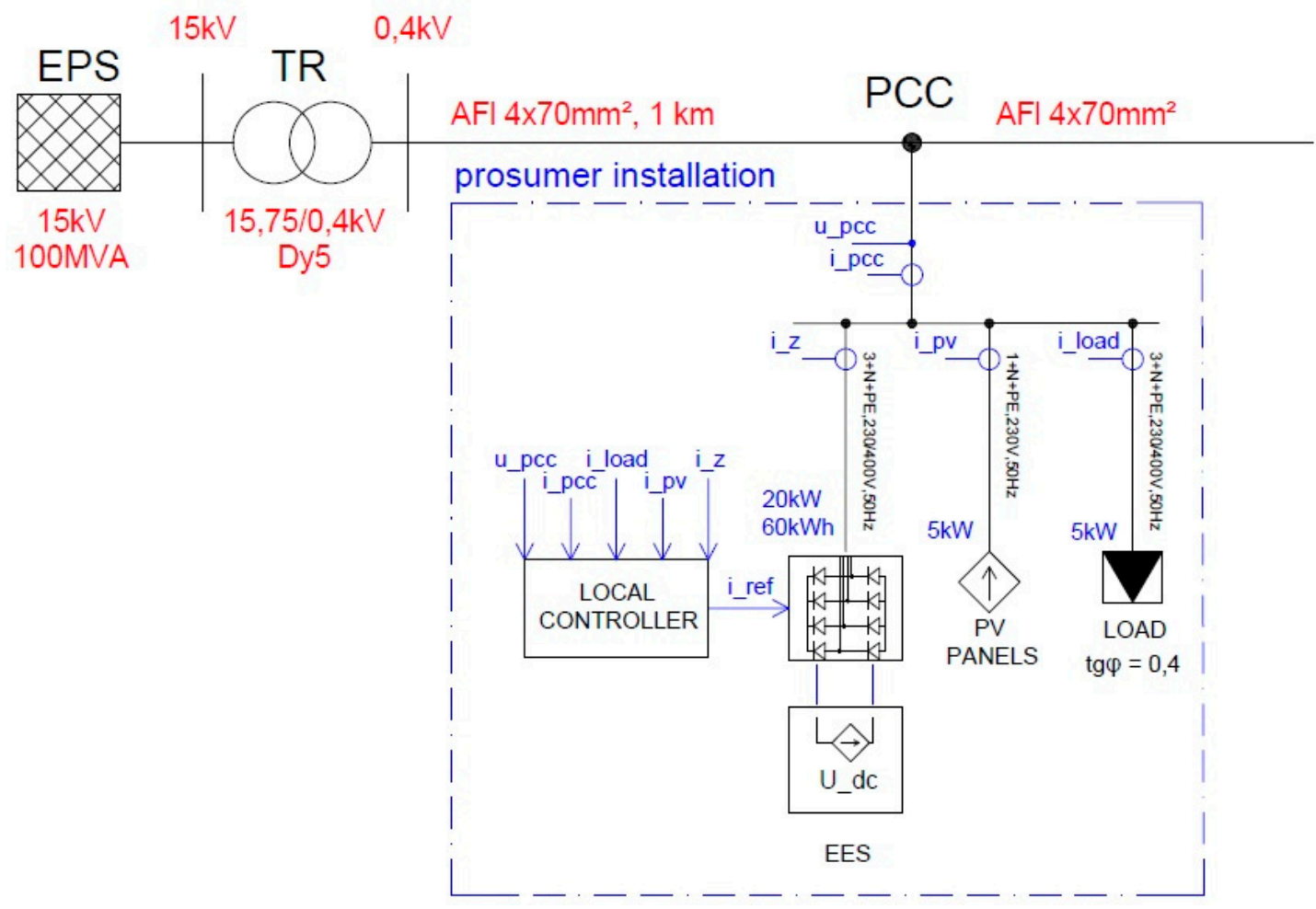

Figure 1. Diagram of the low-voltage (LV) power network with connected prosumer installation (made by authors).

Three schedules of the ESS operation, later called control strategies, were considered for the ESS, differing in terms of an appropriate schedule for charging and discharging of the storage tank. These strategies are described below.

\subsubsection{Strategy 1}

Strategy 1 assumes that the prosumer uses the G12 two-zone tariff for energy billing, in which the energy price is different in two time zones. The billing is based on the 
measurement of the total active power exchanged with the supplying network. The strategy leads to the elimination of the energy imported from the network in the high-price tariff zone. It is therefore assumed that in the low-price tariff zone the electricity demand is covered by the PV generation as well as the electricity drawn from the network and the ESS is being charged. Thus, during this time period both energy consumption as well as energy feeding to the grid are possible.

The value of the ESS charging power is based on the current battery state of charge (SOC) and the duration of the tariff zone:

$$
P_{\text {ref_3ph }}=\frac{E_{e s s} \cdot\left(\mathrm{SOC}_{\mathrm{ref}}-S O C_{0}\right)}{T}
$$

where:

$P_{\text {ref_3ph }}$-ESS charging power

$E_{\text {ess }}$-ESS rated capacity

$\mathrm{SOC}_{\text {ref }}-\mathrm{SOC}$ setpoint at the end of the low-price zone

$S O C_{0}$-initial SOC value at the beginning of the low-price zone

$T$-duration of low-price tariff zone

During the high-price tariff zone, the ESS is discharged with such a power as to balance the power in the prosumer installation. Assuming that the power exchanged with the grid is equal to zero, the ESS reference power results from the equation:

$$
P_{\text {ref_3ph }}=-\sum_{i=1}^{3} \text { Pload }_{i}-\sum_{i=1}^{3} P p v_{i}
$$

where:

$P_{\text {ref_3ph }}$-3-phase ESS charging power

Pload $_{i}$-load power in phase $i$

$P p v_{i}-\mathrm{PV}$ power in phase $i$

A value of the ESS reference power lower than zero means energy generation to the grid, while a value higher than zero means energy consumption from the grid.

\subsubsection{Strategy 2}

The purpose of the ESS working according to Strategy 2 is to maintain a constant active power exchange rate between prosumer installation and the supply network. A value of power exchange lower than zero means energy transmitted to the grid, while power exchange higher than zero means energy consumption from the grid. In order to ensure continuous operation of the ESS, without long-term, fully charged or discharged states, it is assumed that the power exchanged with the network corresponds to the average power of the prosumer plant determined by the following formula:

$$
P_{e x \_3 p h \_a v}=\frac{\int_{0}^{t}\left(\sum_{i=1}^{3} \text { Pload }_{i}+\sum_{i=1}^{3} P p v_{i}\right) d t}{t}
$$

The average power can be determined on the basis of the archived data or forecasts of generation and load profiles for a given period of time (e.g., a day). The charging power of the ESS is derived from the power balance in the installation according to the equation below. According to the strategy, the power exchanged with the grid is equal to or greater than zero.

$$
P_{\text {ref__ } 3 p h}=P_{e_{3 p h a v}}-\sum_{i=1}^{k} \text { Pload }_{i}-\sum_{i=1}^{m} P p v_{i}
$$

where:

$$
P_{e x_{3 p h a v}} \text {-3-phase average value of active power of prosumer installation }
$$


Depending on the relation between the PV source power and load power, the current power of the ESS can be positive (charging) or negative (discharging).

\subsubsection{Strategy 3}

Strategy 3 aims to completely eliminate the transmission of electricity to the grid. In this case, the operation of the ESS is interventional, i.e., the ESS is only loaded when the power generated by the PV is greater than the current consumption power. It is therefore assumed that:

$$
0 \leq P_{\text {ex }} \leq P_{\text {exmax }}
$$

where:

$P_{e x}-3$ phase power drawn from the distribution system

$P_{\text {exmax }}$ - the highest value of 3 phase active power drawn from the network

To ensure that the ESS is always ready for operation, it is necessary to maintain the SOC values within the established limits, beyond which the ESS is discharged or charged to set values (only when the power exchanged with the network is within limits). The condition describing the above-mentioned functionality is presented below:

$$
S O C_{1} \leq S O C \leq S O C_{2}
$$

where:

$S O C_{2}$ - the $S O C$ upper limit value of the $S O C_{\max }$

$S O C_{1}$ - the $S O C$ lower limit value of the $S O C_{\text {min }}$

The implementation of Strategy 3 assumes full use of energy generated by the PV source for the prosumer needs, i.e., the transmission of energy to the power grid is avoided.

\subsection{Modelling and Simulation}

The layout of Figure 1 was modelled in the PSCAD/EMTDC environment and several simulations were performed in order to examine daily active power changes in the installation and show the effects of the implementation of the power management strategies presented above. All simulation studies have been conducted using the infrastructure of the Distributed Generation Laboratory of the Institute of Electrical Power Engineering. All elements of the prosumer installation and the distribution network have been modelled with ready-made elements from PSCAD/EMTDC library.

It should be noted that optimizing the battery size for the best economic result is a separate issue which is beyond the scope of this paper.

The hysteresis method [52,53] was used to control the ESS inverter. Reference currents introduced into the system are determined based on the ESS charging/discharging power. The control algorithm of the ESS takes into account the SOC control. The method of calculating the energy stored in the storage tank and its charge level takes into account energy losses in the storage.

A series of simulations was carried out using the described model. The three ESS control strategies were examined and compared with the case of a prosumer installation not equipped with the ESS. Energy demand profile in the prosumer installation was assumed on the basis of literature [54] and the profile of the PV generation on the basis of the existing PV installation of a similar power, located on one of the buildings of Lodz University of Technology.

Simulation results in Figure 2 show changes in the load power consumption and the PV power generation for the installation without the ESS and change in the voltage value at the PCC. In this case, the distribution network is the only balancing element, resulting in periods of time when power deficit is drawn from the network and periods when surplus power is introduced to the network. The occurrence of single-phase loads and generating infrastructure causes power flow in phases in different directions. In phase L1 the active power surplus is transmitted to the grid, which changes the value of voltage drops and 
increases the voltage in this phase. It should be noted that $1 \mathrm{~s}$ of the simulation corresponds to $1 \mathrm{~h}$ of real time.

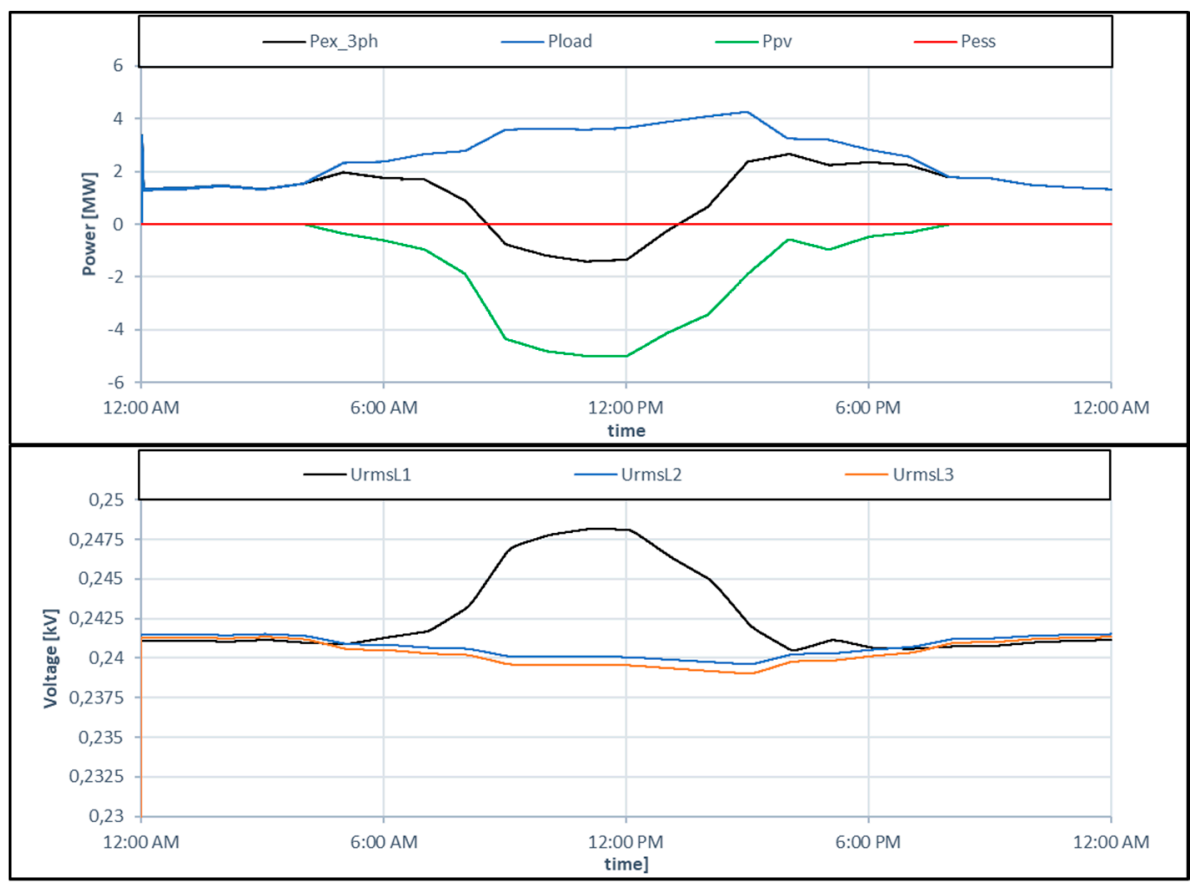

Figure 2. Daily active power balance and voltage changes at the point of common coupling (PCC) of the prosumer installation from Figure 1 without the ESS-results of simulation.

Further simulations were performed for the prosumer installation equipped with the ESS. Figure 3 shows the balance of active power when the control Strategy 1 was applied. In the initial time period, which corresponded to a low-price tariff zone, i.e., from 0:00 a.m. to 6:00 a.m., the ESS was charged with constant power resulting from Equation (1) until fully charged. Then, during a high-price tariff zone (from 6:00 a.m. onwards), no power was imported from the network. During this period, the demand for electricity was covered by both the PV source and the ESS, which caused the ESS to partially discharge. When the value of the power generated by the PV source exceeded the load demand, the surplus energy was accumulated in the ESS, until it was fully charged, i.e., at 12:00 p.m. From that moment the surplus energy was transferred to the network. From 1:00 p.m. onwards, the low-price tariff zone applied again, but the ESS still had no capacity to store any excess energy, so it had to be exported to the network. A gradual decrease in the power generated by the PV source made it necessary to use energy from the ESS to eliminate the energy consumption from the network in the high-price tariff zone between 3:00 p.m. and 10:00 p.m. The ESS was discharged until the low-price tariff zone occurred at 10 p.m., at which point it started charging to the max. SOC value (i.e., 75\%).

Changes in the power exchanged with the network resulted in the corresponding changes of the voltage rms value at the PCC in L1 phase, shown in Figure 3. The small voltage decreases during low-price tariff zone periods (compared to the voltage values in Figure 2) is due to the additional load power required to charge the ESS to the max. SOC level (i.e., 75\%).

Figure 4 shows the balance of the active power in the prosumer installation and changes in the voltage rms value at the PCC with the ESS following Strategy 2. Its aim is to maintain the value of the active power drawn from the grid at a constant level, corresponding to the average power of the prosumer installation determined according to Equation (4). With this method of operation, the energy drawn from the grid and transferred to the grid are constant throughout the entire analysed period, which guarantees that the SOC value at the end of the period will be equal to the initial value. Providing 
a constant value of the power drawn from the network results in the stabilization of the voltage value at the PCC.

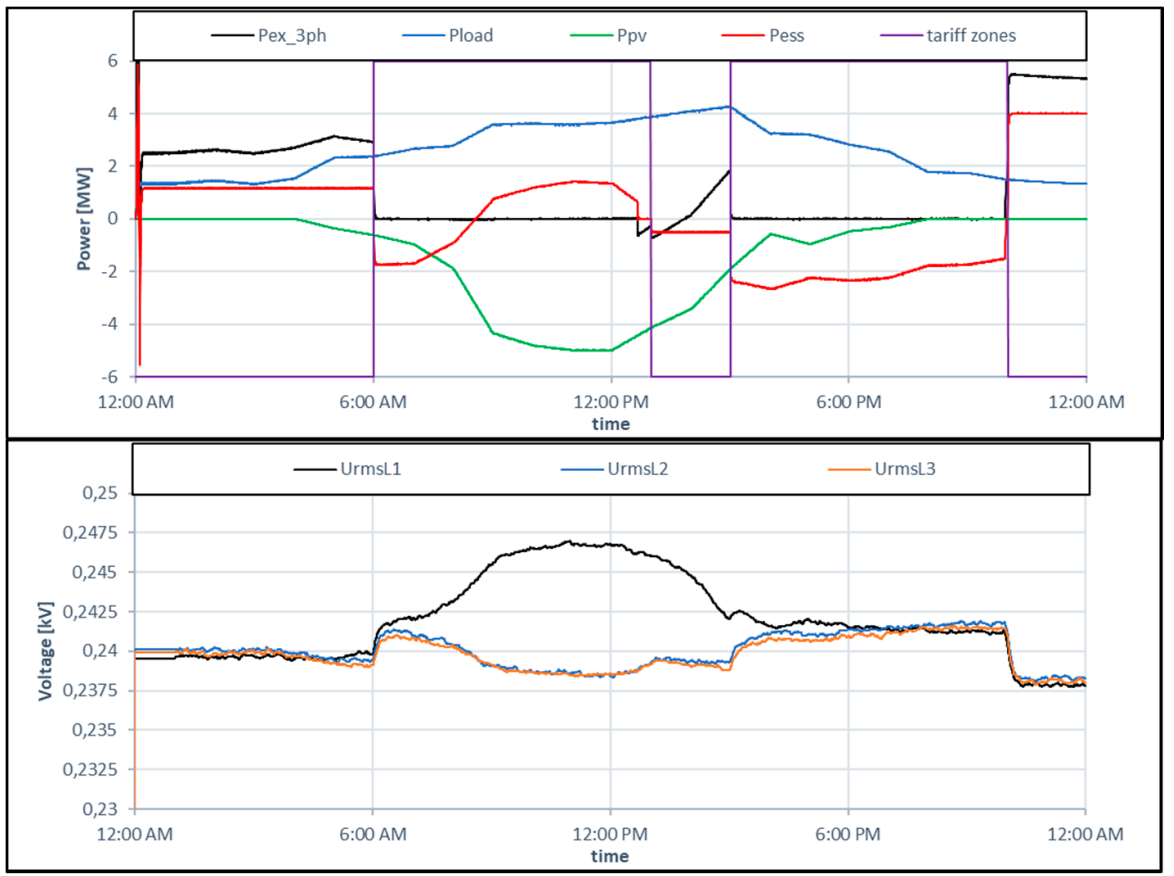

Figure 3. Daily active power balance and voltage changes at the PCC of the prosumer installation with the ESS implementing Strategy 1-results of simulations.

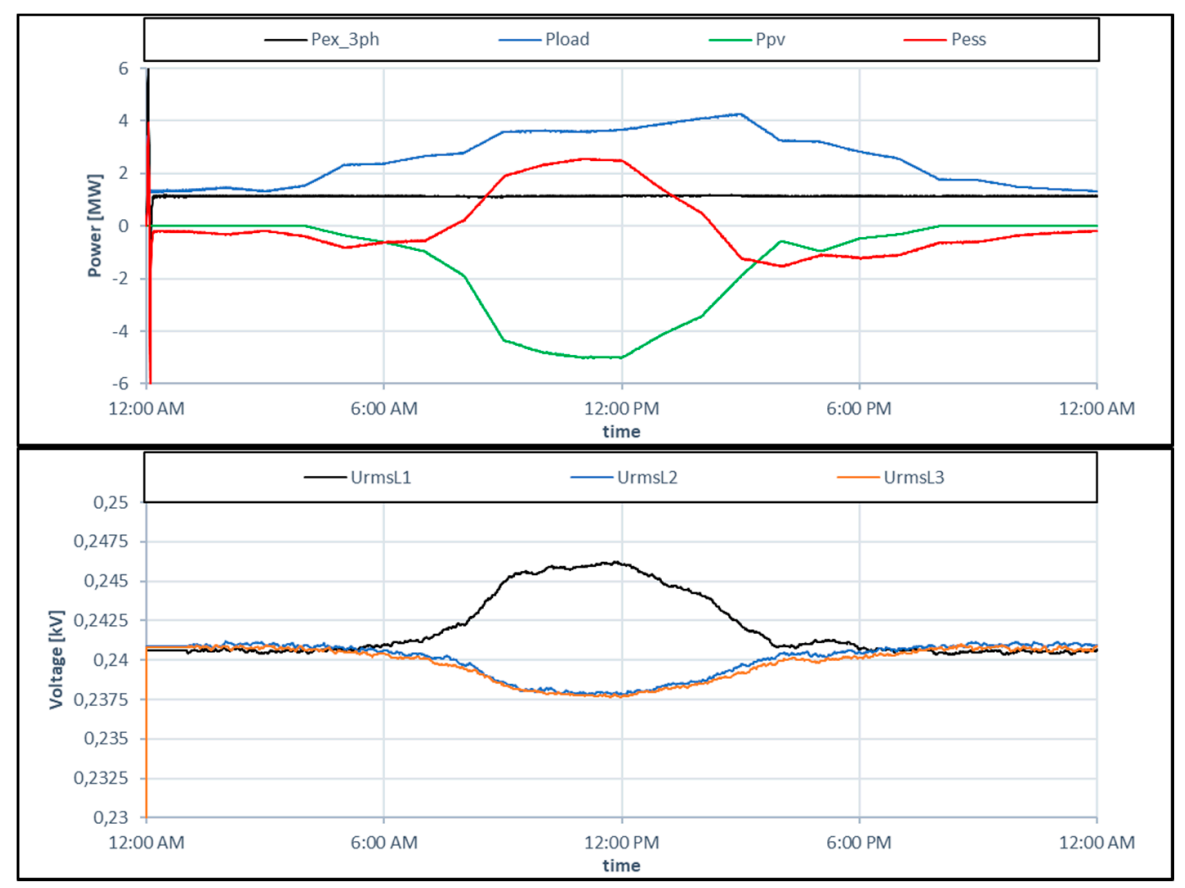

Figure 4. Daily active power balance and voltage changes at the PCC of the prosumer installation with the ESS implementing Strategy 2-results of simulation.

Figure 5 shows the active power balance for the case when Strategy 3 was applied. From the beginning of the simulation until the moment when a surplus of electricity resulting from the PV generation occurred, the ESS did not work. From that moment on, the ESS in line with the assumption of no energy export to the network, stored the surplus 
electricity until the value of the power generated by the PV source was lower than the power consumption. In the subsequent periods the demand for electricity was covered by both the PV and ESS. The ESS was discharged to the initial SOC value of $25 \%$. Changes in the voltage rms value at the PCC resulting from changes in the power consumption from the networks are slightly lower than for Strategy 1 . The voltage decrease at the end of the simulation is due to the ESS being turned off when the required charge level is reached.

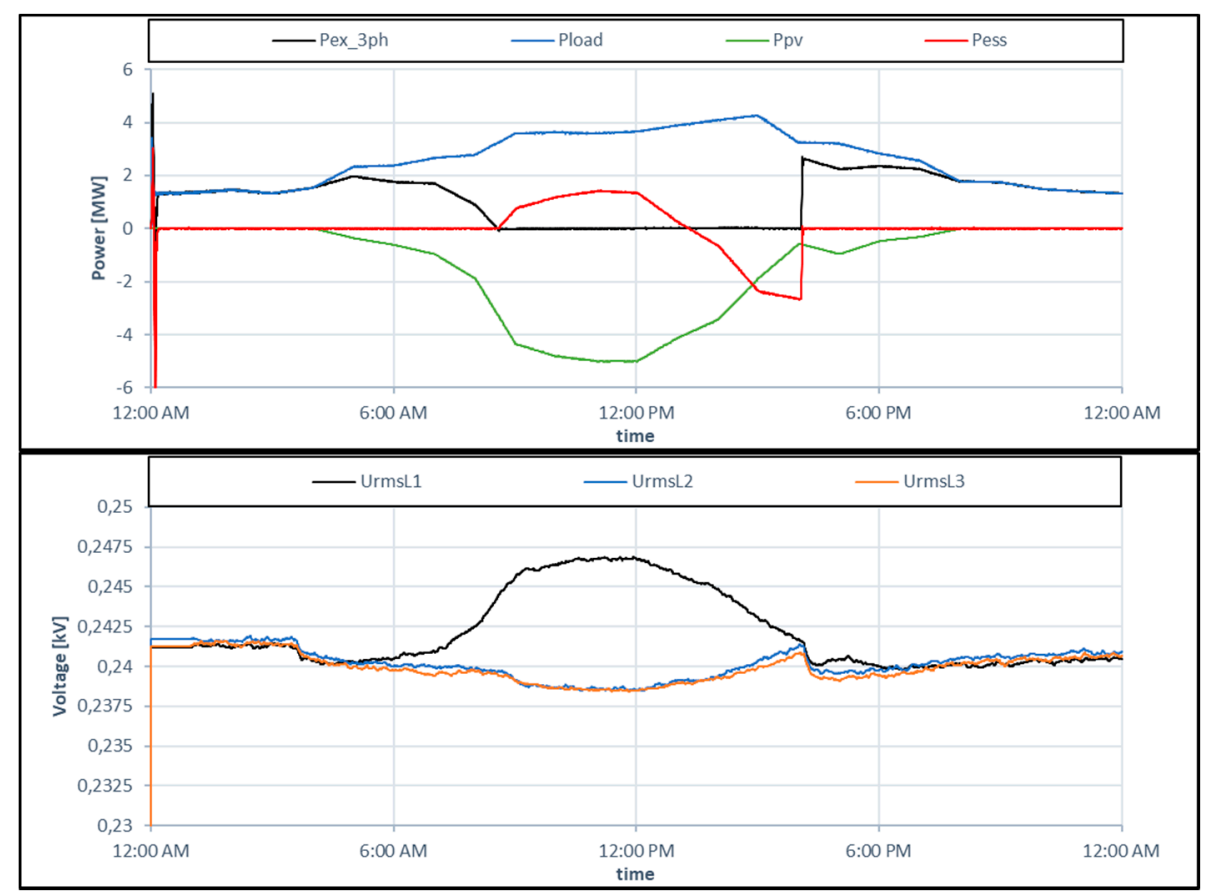

Figure 5. Daily active power balance and voltage changes at the PCC of the prosumer installation with the ESS implementing Strategy 3-results of simulations.

It can be seen from the simulation studies (Figures 2-5) that for the tested installation, strategies developed for the improvement of active power management did not significantly affect the voltage at the PCC. It can be expected that in real prosumer installations, the voltage in the power generation phase will exceed the set limits. The next chapter shows how the algorithm involving the prosumer program can be extended to perform additional control functions dedicated to voltage regulation.

\section{Control of the ESS Inverter for Voltage Regulation}

\subsection{Description}

As mentioned before, the aim of the proposed control strategy is to use the ESS inverter in a prosumer installation to perform voltage regulation simultaneously with the active power management imposed by the prosumer program.

The principle of regulation is the following. The storage inverter located at the node $j$ of the feeder can affect the voltage at the node $i$ through the change of voltage drop $\delta U_{s}$ caused by the flow of storage current $I_{S}=I_{P_{S}}+j I_{Q S}$ through the feeder impedance between these nodes $Z_{i j}$. Assuming that no other currents flow through the feeder change, the voltage drop change $\Delta\left(\delta U_{s}\right)$ can be determined using the following equation:

$$
\Delta\left(\delta U_{s}\right)=R_{i j} \cdot I_{P_{s}}+X_{i j} \cdot I_{Q S}
$$

where:

$R_{i j}$-resistance of the feeder between nodes $i$ and $j$

$X_{i j}$-reactance of the feeder between nodes $i$ and $j$

$I_{P S}$-active component of the ESS current 
$I_{Q s}$-reactive component of the ESS current

There is a linear relationship between active and reactive current components which corresponds to a set value of $\Delta\left(\delta U_{s}\right)$ :

$$
I_{Q s}=-\frac{R_{i j}}{X_{i j}} \cdot I_{P s}+\frac{\Delta\left(\partial U_{s}\right)}{X_{i j}}
$$

where:

$\Delta\left(\delta U_{S}\right)$ - change of voltage drop

$R_{i j}$-resistance of the feeder between nodes $i$ and $j$

$X_{i j}$-reactance of the feeder between nodes $i$ and $j$

On the other side, the phase current of the inverter should not exceed the inverter rated current $I_{n s}$, thus both current components are linked with the following relationship:

$$
I_{P s}^{2}+I_{Q s}^{2} \leq I_{n s}^{2}
$$

where:

$I_{n s}$-rated current of the inverter

$I_{P \mathrm{~s}}$-active component of the ESS current

$I_{\mathrm{Qs}}$-reactive component of the ESS current

The graphical representation of relationships (8) and (9) is shown in Figure 6. Each pair of current components defines the inverter current vector, whose module should not exceed the current rated value. This means that the geometric positions of the ends of the vector are the area within the circle with the radius $I_{n s}$. The points marked in red lying on the straight lines inside the circle satisfy both relationships.

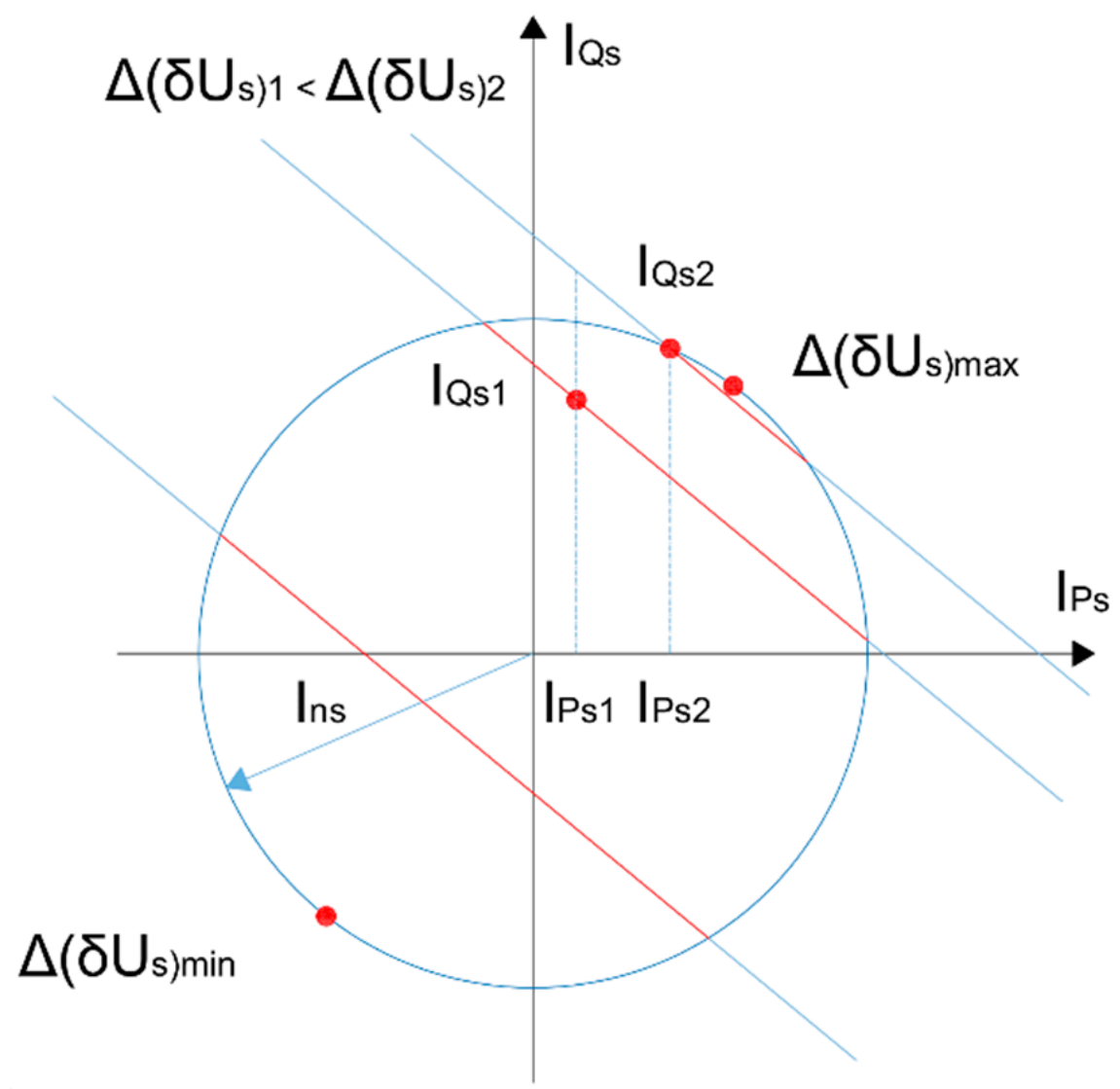

Figure 6. Graphical representation of relationships (8) and (9) (made by authors). 
Figure 6 illustrates an interdependence between the inverter rated current, its active and reactive current components and a voltage drop resulting from the current flow in the feeder. As seen in Figure 6, for the active current $I_{P_{s} 1}$ in a single phase of the inverter, the voltage drop component $\Delta\left(\delta U_{S}\right)_{1}$ is obtained if the reactive current in this phase is set to $I_{Q s 1}$. If an increase of the voltage drop to $\Delta\left(\delta U_{s}\right)_{2}$ is required, then both active and reactive currents should be increased to $I_{P s 2}$ and $I_{Q s 2}$, respectively.

In accordance with the earlier assumptions, the active component of the ESS current results from the 3-phase active power set by the prosumer program schedule, which is evenly distributed into phases. At first, the reactive component is used for the voltage regulation. The value of this current is determined by a local voltage controller in the prosumer installation, which tracks the voltage at the PCC and, when a deviation from the voltage nominal value is detected, forces the reactive current to change so as to cause an appropriate change of the voltage drop on the feeder reactance. The regulation is performed in each phase independently because phase voltages at the PCC differ due to the load current unbalance in the network.

Assuming that the prosumer program takes priority and the ESS active currents cannot be changed, reactive currents are determined only within the limits defined by the area of the circle in Figure 6. For this reason, voltage regulation by means of reactive current only may by ineffective in LV networks with low $\mathrm{X} / \mathrm{R}$ ratio. The proposed method allows active current to be included in the voltage regulation without altering the 3-phase active power of the ESS.

It is permitted to change the ESS active current in a phase in which the voltage regulation is carried out. If the change of the active current component in one phase is required from $I_{P_{s} 1}$ to $I_{P_{s} 2}$, then this change is compensated for by appropriate changes in other phases, i.e., $0.5 *\left(I_{P_{s} 1}-I_{P_{s} 2}\right)$, so that the total active power required by the prosumer program remains unchanged. If the action is not possible due to currents reaching their rated values, then the voltage service is stopped and the prosumer program is continued without interruptions. Maximum regulation capabilities of the inverter are reached when the current vector moves in a circle to the points of $\Delta\left(\delta U_{s}\right)_{\max }$ or $\Delta\left(\delta U_{s}\right)_{\min }$. The proposed approach does not reduce the prosumer's benefits due to the active power management and at the same time ensures the improvement of voltage at the connection point in the range possible to obtain.

The effects of voltage regulation using the described methods are evaluated and compared in the next section.

\subsection{Control Effects}

Test calculations were performed for the evaluation of the control method described in Section 3.1 using a simulator of the simplified system shown in Figure 7. The simulator was developed in the PSCAD/EMTDC environment. Tested control methods were implemented in the Storage Inverter Control block shown in the figure. Block input signals are the active current $I_{\text {Pin }}$ dependent on the prosumer program and determined in the Prosumer Program block and the reactive current $I_{Q i n}$ required for the voltage regulation and determined in the Voltage Controller block. Both quantities are vectors of three elements corresponding with the three phases of the storage inverter. To check the control range, signals in one phase only were changed during tests; all other components of the input vectors were equal to zero.

From the Storage Inverter Control block the components of reference currents $I_{\text {ref }}$ are generated for each phase of the storage inverter. Inverter output currents: $I_{S}=I_{P S}+j I_{Q s}$ follow their references and their flowing through the feeder causes the voltage drop $\delta U_{S}$ on the feeder impedance $R+j X$ (currents flowing from other devices are omitted).

Input signals to the Storage Inverter Control block generated by the PSCAD signal generators were assumed to be periodical, so as to check the whole range of variations in the regulation effects. The active current component was a triangular function with a period of $100 \mathrm{~s}$ and the maximum value equal to the inverter rated current $0.015 \mathrm{kA}$. The 
reactive current component was a triangular function with a period of $1 \mathrm{~s}$. Input signals were applied only to phase L3 of the inverter and were the same in all tests.

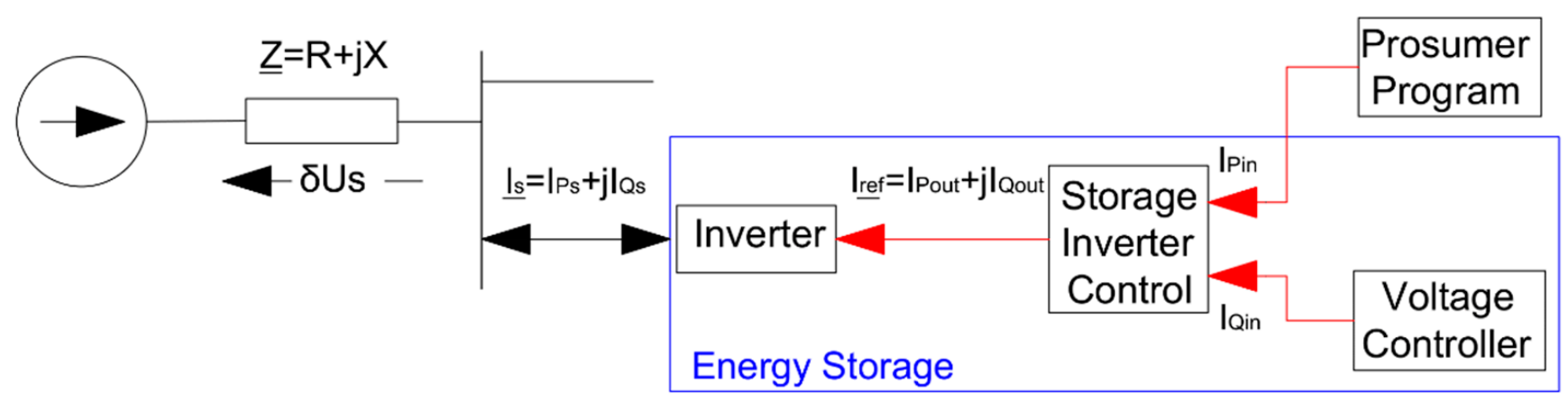

Figure 7. Diagram of a test system used for the evaluation of the proposed inverter control method.

Two features were examined during the tests to evaluate the performance of the method. The first one was to check whether the reference current determined for the inverter phase L3 ensured that its output current did not exceed its rated value. For this purpose, a hodograph of the reference current was observed throughout each simulation. Its components were designated as $I_{\text {Pout } L 3}$ and $I_{Q \text { Qut L3 }}$. The second examined feature was the voltage effect achieved for the changes in the active power resulting from the assumed method. The effect was evaluated on the basis of a graph showing the voltage drop $\delta U_{S}$ as a function of the 3-phase inverter power, whose measure was the sum of the reference current active components $I_{\text {Pout }}$ ( $X$ axis in the drawings) determined for three phases in the subsequent moments of the simulation. The results of simulation tests are shown in Figure 8.

The hodographs of the reference current vector for phase L3 have been placed on the left side in Figure 8 and the voltage drops are on the right side. Figure 8B,C relate to the case when the change of active power is not permitted, and Figure $8 \mathrm{D}, \mathrm{E}$ show the results for the case when the proposed method was applied.

The shape of current hodographs (Figure 8B,D) indicates that the relationship (3) was met in both cases. A comparison of charts in Figure 8C,E clearly shows a considerably greater range of voltage changes for the proposed method. It is possible to obtain voltage drops $\delta U$ ( $Y$ axis in the drawings) in the range of $\delta U_{s m i n}, \delta U_{s m a x}$ in the controlled phase without changing the 3-phase inverter power set by the prosumer program. It should be noted that in the described tests, the ESS currents were the only ones causing the voltage drop in the feeder. Thus, in this case the change in the voltage drop corresponded to the voltage variations at the point of connection. 


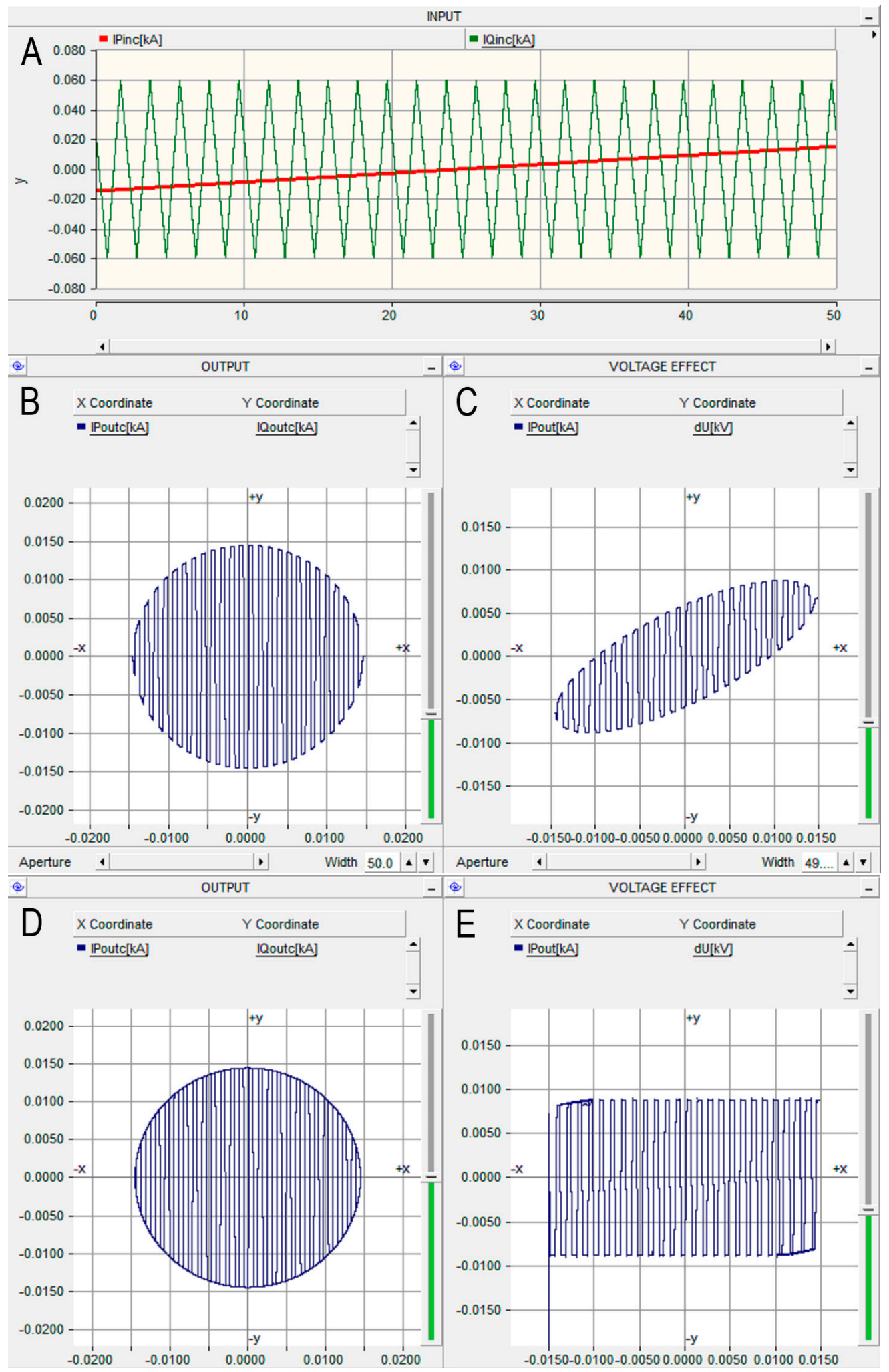

Figure 8. Results of evaluation tests of the proposed regulation method. (A) reference signals of active and reactive currents for the inverter; (B) inverter active and reactive current values when the change of active power is not permitted; (C) — changes of voltage value depending on inverter active current for the case when the change of active power is not permitted; (D) inverter active and reactive current values when the change of active power is permitted; (E) changes of voltage value depending on inverter active current for the case when the change of active power is permitted. 


\section{Application of the ESS with the Extended Control Algorithm in a Prosumer Installation}

\subsection{Description of Tests}

In this section the results of simulations are presented showing the application of the proposed voltage control method together with the active power management program for an ESS connected to the prosumer installation in the LV network. A simulator was built in the PSCAD program for the system shown in Figure 9. The prosumer installation included a single-phase load device (Load) connected to phase L2, a single-phase photovoltaic source $(\mathrm{PhV})$ connected to phase L1 and an energy storage with a 3-phase inverter (Storage).

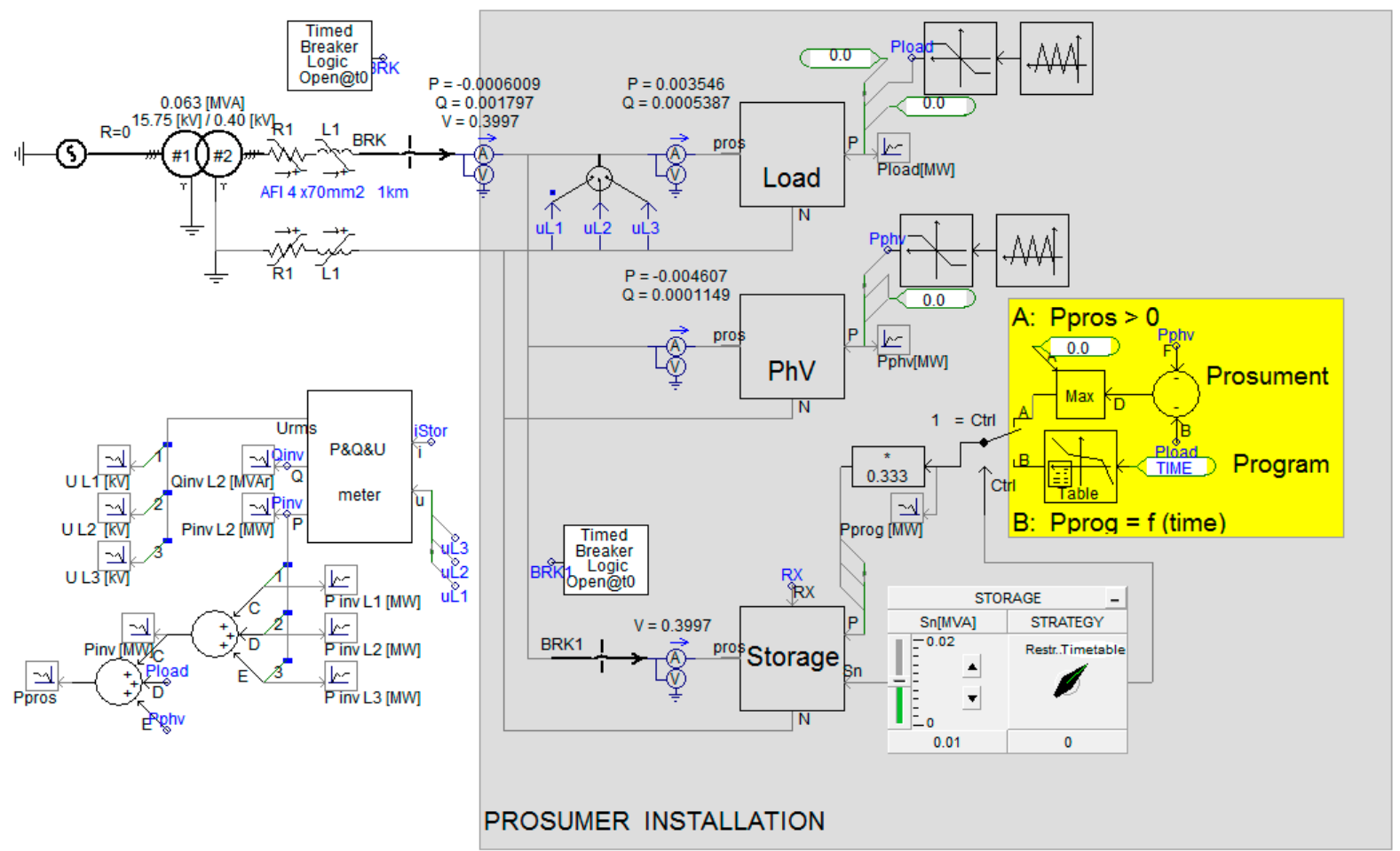

Figure 9. Diagram of the simulator developed in PSCAD/EMTDC environment.

Two tests were carried out for different prosumer programs. In both of them the active power consumed by the load and the power generated by the PV source changed according to the assumed profiles. Load devices followed a quasisawtooth consumption profile, e.g., from zero to the maximum power of $5 \mathrm{~kW}$ and back to zero with the period of changes equal to $10 \mathrm{~s}$ of the simulation time. The PV source followed a quasitrapezoidal generation profile with the period of changes equal to $30 \mathrm{~s}$. The load reactive powers of both devices were equal to zero.

It should be noted that the power profiles, deviating from standard profiles, have been defined specifically for testing. They were intended to show the possible effects of the storage control, in accordance with the proposed method, when the demand power changes occur more often than the changes in the generation.

The ESS operated in accordance with the prosumer program, so its active power was set according to the chosen strategy. Two of the strategies described in Section 2 were considered: Strategy $1\left(P_{\text {pros }}=f(\right.$ time $)$ in the first test and Strategy $3\left(P_{\text {pros }}>0\right)$ in the second test. Their implementation in the prosumer program resulted in the $\mathrm{P}_{\text {prog }}$ power profile according to which the ESS is controlled. The strategies were selected using the block Two Input Selector in Figure 9.

During both tests, the reactive power causing the voltage effect was calculated for each inverter phase separately as a linear function of the voltage deviation from the nominal value measured at the PCC in that phase. 
The results of tests are presented in Figures 10 and 11 and discussed in the next section.

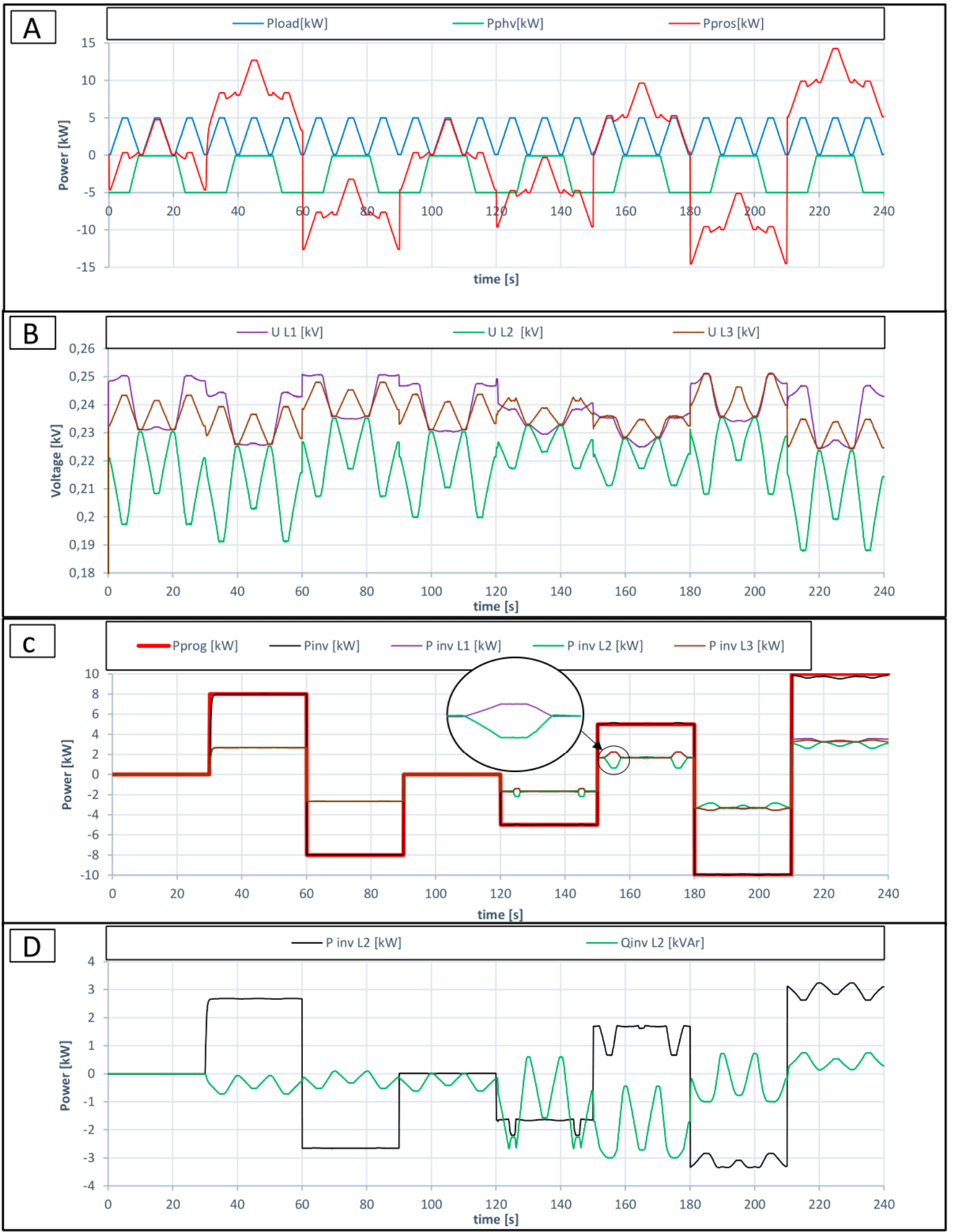

Figure 10. Simulation results with the prosumer program Strategy 1. (A) active powers of loads, PV installations and the prosumer program; (B) rms values of voltages in PCC; $(\mathbf{C})$ inverter reference active power and active power realized by the inverter; (D) active and reactive power in $\mathrm{L} 2$ phase of the inverter. 


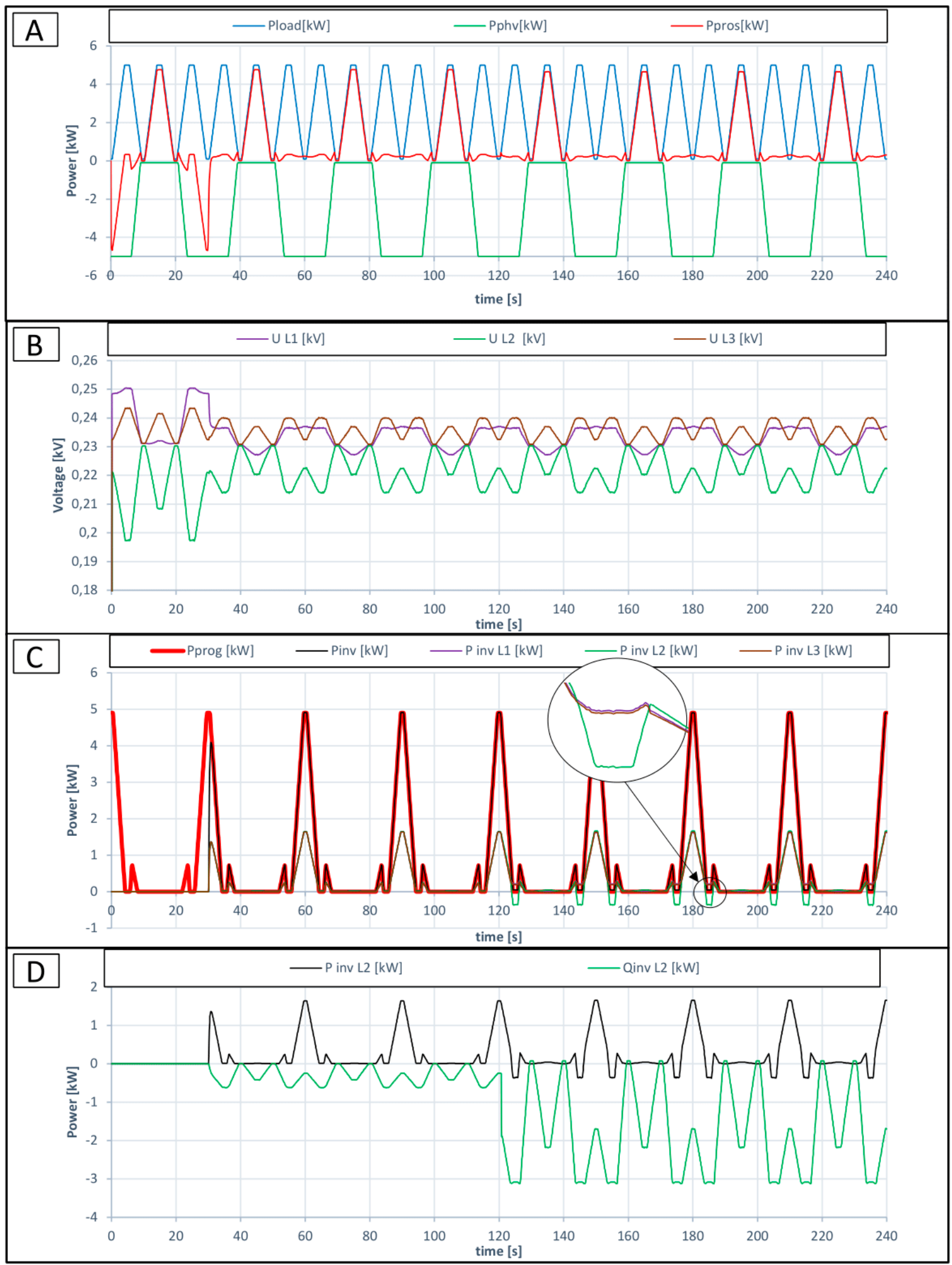

Figure 11. Simulation results with the prosumer program Strategy 3. (A) active powers of loads, PV installations and the prosumer program; (B) rms values of voltages in PCC; $(\mathbf{C})$ inverter reference active power and active power realized by the inverter; (D) active and reactive power in $\mathrm{L} 2$ phase of the inverter. 


\subsection{Discussion of the Results}

The profiles of the load active power $P_{\text {load }}$ and the PV active power $P_{\text {phv }}$ are shown in the upper parts of Figures 10 and 11. In the first test (Figure 10) the simulation period was divided into equal low tariff and high tariff zones that alternate. The ESS inverter was turned on after $30 \mathrm{~s}$ and up to $120 \mathrm{~s}$ performed only active power management consisting of the execution of active power reference signals calculated for each tariff zone. The variations of voltage values during this period resulted from the change in active power balance. It is clearly visible in Figure 10 that after switching the voltage regulation on, voltage variations in phase L2 (a single-phase load connected to this phase) were reduced. It influenced the regulation of the phase active powers of the inverter and their departure from the subsequent set value, which was $1 / 3$ of the $P_{\text {prog }}$ value. Nonetheless, the total active power $P_{\text {inv }}$ remained unchanged due to active power compensation in other phases and corresponded to the set value $\mathrm{P}_{\text {prog }}$ (Figure 10C). Voltage regulation ceased at $180 \mathrm{~s}$, when the inverter active power reached the rated apparent power of 0.01 MVA. As a result, no reactive current component could be generated in any phase and the inverter had no available power for further voltage regulation.

In the second test (Figure 11) the inverter was switched on after $30 \mathrm{~s}$. Up to $120 \mathrm{~s}$, the inverter performed only active power management. After switching on the voltage regulation, voltage variations in phase L2 decreased but it did not influence the phase active power of the inverter controlled in accordance with the prosumer strategy. Voltage reduction was accomplished in the whole simulation because the inverter active power did not exceed half of its rated apparent power.

Figures 10 and 11 illustrate the operation of the inverter control system. Small voltage variations are compensated for only by the use of the reactive power in the controlled phase (Figures 10D and 11D). Major variations additionally need the change of active power in a given phase and corrections of power in other changes so that the 3-phase power of the inverter remains equal to the prosumer program. These actions are visible in the phase active powers of the ESS (marked in blue, green and yellow) in Figures 10C and 11C. In Figures $10 \mathrm{C}$ and $11 \mathrm{C}$, the inverter phase powers in phase L1 and L3 overlap, making the blue curve invisible. The voltage regulation stops when the storage inverter is fully loaded because of the selected prosumer program (Figures 10B and 11B).

The presented research has shown that all considered control strategies applied to the ESS in the prosumer installation may improve the utilization of energy generated by the PV source for local purposes. The choice of a strategy optimal for the prosumer requires knowledge about electricity tariffs as well as consumption and generation power profiles of the load equipment and energy sources. It also includes the selection of inverter power and energy storage capacity as well as the calculation of investment costs. The selection of the best investment variant may be made on the basis of the results of simulation tests mapping the operation of all equipment in the prosumer's installation and calculating both the operating and fixed costs of the tested variant. However, the ESS applied for managing the active power in the prosumer installation only to bring benefits to the prosumer leaves the problem of excessive voltage values at the PCC out of control. Even if the transmission of energy to the network is eliminated, the voltage value may still be beyond permissible limits and the voltage quality in individual phases may not be acceptable.

It has been demonstrated that with the additional control proposed in the paper and applied to the ESS installation, the voltage problem can be mitigated without compromising the effects of the prosumer program. While the ESS prioritizes the strategy selected by the prosumer following a set schedule of charging and discharging, the network service is provided by using the available power of the ESS inverter.

The simulations have shown a case where the reactive power control alone is not sufficient. The use of both reactive and active power by interfering with the local algorithm of the active power management proved necessary. 


\section{Conclusions}

In the face of the constantly increasing power of PV installations, the negative influence of prosumers is no longer an expectation but reality. Installations intended to bring savings for investors and relieve the burden on the professional power industry cause interruption of the PV installation operation, reverse power flows and result in the deterioration of power quality. It is now necessary to transform prosumer installations into active regulatory tools, enabling the compensation of the negative impact of PV. This article offers one of the possibilities to maintain a full PV generation potential while providing voltage control in the network by using the ESS in the prosumer installation. The proposed control algorithm enables disturbance-free operation of the ESS for the prosumer with simultaneous voltage regulation capability.

The novelty proposed in this article is the method of compensating for the active power loss in the phase where the voltage is regulated by the remaining phases, so that the 3-phase energy exchanged with the grid remains unchanged. Simulation studies have proven that the value of 3-phase energy exchanged with the grid is unchanged despite the use of active power in one of the phases for voltage regulation purposes.

The presented approach is beneficial for the prosumer both from the economic (cost reduction) and technical (overvoltage mitigation and preventing the PV inverter from disconnection) point of view. It is also beneficial for the network operator as a means to help maintain the required power quality. The regulation service should be performed on a market basis.

It is worth noting that many prosumers in the network may already be equipped with a storage installation. If the controllers suggested in this paper are implemented, the regulation service for the distribution network can be provided at no additional cost, assuming that the service is realized without interfering with the prosumer's own management strategies.

The proposed method is particularly suitable for low-voltage networks, characterized by the load unbalance resulting from single-phase loads and sources installed in prosumer/consumer installations. As the control system distributes the active power generated by the prosumer program into three phases, the method makes it possible to compensate for the current and voltage unbalance as an indirect effect.

Further development of the presented method may include extending the local algorithm of active power management to reactive power management and power quality improvement while implementing voltage regulation in several prosumer installations in a coordinated manner.

Author Contributions: P.U.: investigation, simulation, writing_original draft, formal analysis; R.M.: investigation, simulation, validation, writing—original draft; I.W.: conceptualization, methodology, supervision, writing - final preparation. All authors have read and agreed to the published version of the manuscript.

Funding: This work has been founded by the Polish National Centre for Research and Development and cofinanced by the European Regional Development under Smart Growth Operational Program 2014-2020 under the project POIR.04.01.02-00-0007/17.

Data Availability Statement: Data available on request due to restrictions eg privacy or ethical. The data presented in this study are available on request from the corresponding author. The data are not publicly available due to ongoing research on the topic presented in the article.

Acknowledgments: This work has been founded by the Polish National Centre for Research and Development and cofinanced by the European Regional Development under Smart Growth Operational Program 2014-2020 under the project POIR.04.01.02-00-0007/17.

Conflicts of Interest: The authors declare no conflict of interest. 


\section{References}

1. Manz, D.; Walling, R.; Miller, N.; Larose, B.; D'Aquila, R.; Daryanian, B. The grid of the future: Ten trends that will shape the grid over the next decade. IEEE Power Energy Mag. 2014, 12, 26-36. [CrossRef]

2. Farhangi, H. The path of the smart grid. IEEE Power Energy Mag. 2010, 8, 18-28. [CrossRef]

3. Strbac, G.; Aunedi, M.; Pudjianto, D.; Djapic, P.; Teng, F.; Sturt, A.; Jackravut, D.; Sansom, R.; Yufit, V.; Brandon, N. Strategic Assessment of the Role and Value of Energy Storage Systems in the UK Low Carbon Energy Future Report for. Carbon Trust 2012, 1-99. Available online: https://www.researchgate.net/profile/Vladimir_Yufit/publication/304998523_Strategic_assessment_of_ the_role_and_value_of_energy_storage_systems_in_the_UK_low_carbon_energy_future/links/5783768108ae37d3af6bedab / Strategic-assessment-of-the-role-and-value-of-energy-storage-systems-in-the-UK-low-carbon-energy-future.pdf (accessed on 12 January 2021).

4. Ofgem; DECC. Smart Grid Forum Smart Grid Vision and Routemap Smart Grid Forum. Rep. Number URN 14D/056, February 2014. Available online: https://assets.publishing.service.gov.uk/government/uploads/system/uploads/attachment_data/file/ 285417/Smart_Grid_Vision_and_RoutemapFINAL.pdf (accessed on 12 January 2021).

5. Farmanbar, M.; Parham, K.; Arild, O.; Rong, C. A widespread review of smart grids towards smart cities. Energies 2019, $12,4484$. [CrossRef]

6. Espe, E.; Potdar, V.; Chang, E. Prosumer communities and relationships in smart grids: A literature review, evolution and future directions. Energies 2018, 11, 2528. [CrossRef]

7. Aguero, J.R.; Takayesu, E.; Novosel, D.; Masiello, R. Modernizing the Grid: Challenges and Opportunities for a Sustainable Future. IEEE Power Energy Mag. 2017, 15, 74-83. [CrossRef]

8. Zia, M.F.; Benbouzid, M.; Elbouchikhi, E.; Muyeen, S.M.; Techato, K.; Guerrero, J.M. Microgrid transactive energy: Review, architectures, distributed ledger technologies, and market analysis. IEEE Access 2020, 8, 19410-19432. [CrossRef]

9. Gough, M.; Santos, S.F.; Javadi, M.; Castro, R.; Catalão, J.P.S. Prosumer flexibility: A comprehensive state-of-the-art review and scientometric analysis. Energies 2020, 13, 2710. [CrossRef]

10. Jäger-Waldau, A. PV Status Report 2019; EUR 29938 EN; Publications Office of the European Union: Luxembourg, 2019; ISBN 978-92-76-12608-9. [CrossRef]

11. Keiner, D.; Ram, M.; Barbosa, L.D.S.N.S.; Bogdanov, D.; Breyer, C. Cost optimal self-consumption of PV prosumers with stationary batteries, heat pumps, thermal energy storage and electric vehicles across the world up to 2050. Sol. Energy 2019, 185, 406-423. [CrossRef]

12. Ulbig, A.; Rullan, T.; Koch, S.; Ferrucci, F. Assessment of aggregated impacts of prosumer behaviour. IET Conf. Publ. 2016, 2016, 4-7. [CrossRef]

13. Vallée, F.; Klonari, V.; Lobry, J.; Durieux, O. Study of the combined impact of auto-consumption behaviour and correlation level between prosumers on overvoltage probabilities in low voltage distribution grids. In Proceedings of the 2014 IEEE PES T\&D Conference and Exposition, Chicago, IL, USA, 14-17 April 2014; pp. 1-6. [CrossRef]

14. Nousdilis, A.I.; Nikolaou, A.A.; Kontis, E.O.; Kryonidis, G.C.; Christoforidis, G.C.; Papagiannis, G.K. A Sizing Method for Decentralized Energy Storage Systems Operating under a Peak Shaving Control Strategy. In Proceedings of the 2018 53rd International Universities Power Engineering Conference (UPEC), Glasgow, UK, 4-7 September 2018; pp. 1-6.

15. Nizami, M.S.H.; Haque, A.N.M.M.; Nguyen, P.H.; Bliek, F.W. HEMS as network support tool: Facilitating network operator in congestion management and overvoltage mitigation. In Proceedings of the 2016 IEEE 16th International Conference on Environment and Electrical Engineering (EEEIC), Florence, Italy, 7-10 June 2016; pp. 1-6. [CrossRef]

16. Nousdilis, A.I.; Chrysochos, A.I.; Papagiannis, G.K.; Christoforidis, G.C. The impact of Photovoltaic Self-Consumption Rate on voltage levels in LV distribution grids. In Proceedings of the 2017 11th IEEE International Conference on Compatibility, Power Electronics and Power Engineering (CPE-POWERENG), Cadiz, Spain, 4-6 April 2017; pp. 650-655.

17. Nousdilis, A.I.; Papagiannis, G.K.; Christoforidis, G.C. Investigating the impact of decentralized energy storage systems in active low-voltage distribution networks. In Proceedings of the 2017 52nd International Universities Power Engineering Conference (UPEC), Heraklion, Greece, 28-31 August 2017; pp. 1-6. [CrossRef]

18. Baran, M.E.; Hooshyar, H.; Shen, Z.; Huang, A. Accommodating high PV penetration on distribution feeders. IEEE Trans. Smart Grid 2012, 3, 1039-1046. [CrossRef]

19. Hoffmann, A.; Fleckenstein, M.; Balzer, G.; Hartkopf, T. Grid services with PV-converters in distribution systems. In ISGT 2014; IEEE: Washington, DC, USA, 2014; pp. 1-5. [CrossRef]

20. Pompodakis, E.E.; Drougakis, I.A.; Lelis, I.S.; Alexiadis, M.C. Photovoltaic systems in low-voltage networks and overvoltage correction with reactive power control. IET Renew. Power Gener. 2016, 10, 410-417. [CrossRef]

21. Muzi, F.; Calcara, L.; Pompili, M.; Sangiovanni, S. The New Prosumer Tasks in the Energy Management of Buildings. In Proceedings of the 2018 IEEE International Conference on Environment and Electrical Engineering and 2018 IEEE Industrial and Commercial Power Systems Europe (EEEIC / I\&CPS Europe), Palermo, Italy, 12-15 June 2018; pp. 1-4. [CrossRef]

22. Wang, L.; Yan, R.; Saha, T.K. Voltage regulation challenges with unbalanced PV integration in low voltage distribution systems and the corresponding solution. Appl. Energy 2019, 256, 113927. [CrossRef]

23. Ghasemi, M.A.; Parniani, M. Prevention of distribution network overvoltage by adaptive droop-based active and reactive power control of PV systems. Electr. Power Syst. Res. 2016, 133, 313-327. [CrossRef] 
24. Zeraati, M.; Hamedani Golshan, M.E.; Guerrero, J.M. Distributed Control of Battery Energy Storage Systems for Voltage Regulation in Distribution Networks with High PV Penetration. IEEE Trans. Smart Grid 2018, 9, 3582-3593. [CrossRef]

25. Vatu, R.; Ceaki, O.; Mancasi, M.; Porumb, R.; Seritan, G. Analysis of ancillary services within smart grid framework. 2015 In Modern Electric Power Systems (MEPS); IEEE: Wroclaw, Poland, 2015; pp. 1-5. [CrossRef]

26. Carpinelli, G.; Mottola, F.; Proto, D.; Varilone, P. Minimizing unbalances in low-voltage microgrids: Optimal scheduling of distributed resources. Appl. Energy 2017, 191, 170-182. [CrossRef]

27. Bignucolo, F.; Caldon, R.; Pesavento, N.; Savio, A. House to grid (H2G) ancillary services supplied by next generation AC/DC household systems. In Proceedings of the 2017 AEIT International Annual Conference, Cagliari, Italy, 20-22 September 2017; pp. 1-6. [CrossRef]

28. Busarello, T.D.C.; Paredes, H.K.M.; Pomilio, J.A.; Simões, M.G. Synergistic operation between Battery Energy Storage and photovoltaic generator systems to assist management of microgrids. IET Gener. Transm. Distrib. 2018, 12, 1-10. [CrossRef]

29. Behravesh, V.; Keypour, R.; Akbari Foroud, A. Control strategy for improving voltage quality in residential power distribution network consisting of roof-top photovoltaic-wind hybrid systems, battery storage and electric vehicles. Sol. Energy 2019, 182, 80-95. [CrossRef]

30. De La Nieta, A.A.S.; Gibescu, M. Day-ahead Scheduling in a Local Electricity Market. In Proceedings of the 2019 International Conference on Smart Energy Systems and Technologies (SEST), Porto, Portugal, 9-11 September 2019; pp. 1-6. [CrossRef]

31. Luna, A.C.; Diaz, N.L.; Graells, M.; Vasquez, J.C.; Guerrero, J.M. Cooperative energy management for a cluster of households prosumers. IEEE Trans. Consum. Electron. 2016, 62, 235-242. [CrossRef]

32. Almenning, O.M.; Bjarghov, S.; Farahmand, H. Reducing Neighborhood Peak Loads with implicit Peer-to-Peer energy trading under Subscribed Capacity tariffs. In Proceedings of the 2019 International Conference on Smart Energy Systems and Technologies (SEST), Porto, Portugal, 9-11 September 2019; pp. 1-6. [CrossRef]

33. Dukovska, I.; Paterakis, N.G.; Slootweg, H.J.G. Coordination for Prosumers' Electricity Trading Agents via Distributed Optimization. In Proceedings of the 2019 International Conference on Smart Energy Systems and Technologies (SEST), Porto, Portugal, 9-11 September 2019; pp. 1-6. [CrossRef]

34. Lilla, S.; Orozco, C.; Borghetti, A.; Napolitano, F.; Tossani, F. Day-ahead scheduling of a local energy community: An alternating direction method of multipliers approach. IEEE Trans. Power Syst. 2019. [CrossRef]

35. Macana, C.A.; Pota, H.R. Optimal energy management system for strategic prosumer microgrids: An average bidding algorithm for prosumer aggregators. In Proceedings of the 2017 11th Asian Control Conference (ASCC), Gold Coast, QLD, Australia, 17-20 December 2017; pp. 705-710. [CrossRef]

36. Mike, D.; Lagler, A. Influence of Optimizing Prosumers on Urban Distribution Networks. In Proceedings of the International ETG-Congress 2019; ETG Symposium, Esslingen, Germany, 8-9 May 2019; pp. 1-5.

37. Liu, N.; Cheng, M.; Yu, X.; Zhong, J.; Lei, J. Energy-Sharing Provider for PV Prosumer Clusters: A Hybrid Approach Using Stochastic Programming and Stackelberg Game. IEEE Trans. Ind. Electron. 2018, 65, 6740-6750. [CrossRef]

38. Chung, K.; Hur, D. Towards the Design of P2P Energy Trading Scheme Based on Optimal Energy Scheduling for Prosumers. Energies 2020, 13, 5177. [CrossRef]

39. Radl, J.; Fleischhacker, A.; Revheim, F.H.; Lettner, G.; Auer, H. Comparison of Profitability of PV Electricity Sharing in Renewable Energy Communities in Selected European Countries. Energies 2020, 13, 5007. [CrossRef]

40. Chung, M.H. Comparison of economic feasibility for efficient peer-to-peer electricity trading of PV-equipped residential house in korea. Energies 2020, 13, 3568. [CrossRef]

41. Ledva, G.S.; Vrettos, E.; Mastellone, S.; Andersson, G.; Mathieu, J.L. Applying networked estimation and control algorithms to address communication bandwidth limitations and latencies in demand response. In Proceedings of the 201548 th Hawaii International Conference on System Sciences, Kauai, HI, USA, 5-8 January 2015; pp. 2645-2654. [CrossRef]

42. Kusakana, K. Modeling an optimal peer-to-peer energy sharing between prosumers in a south african context. In Proceedings of the 2019 IEEE Milan PowerTech, Milan, Italy, 23-27 June 2019; pp. 1-6. [CrossRef]

43. Wongwut, K.; Nuchprayoon, S. Optimum hourly operation of a prosumer with battery energy storage system under time-of-use pricing. In Proceedings of the 2017 IEEE PES Asia-Pacific Power and Energy Engineering Conference (APPEEC), Bangalore, India, 8-10 November 2017; pp. 1-6. [CrossRef]

44. Azar, A.G.; Nazaripouya, H.; Khaki, B.; Chu, C.C.; Gadh, R.; Jacobsen, R.H. A Non-Cooperative Framework for Coordinating a Neighborhood of Distributed Prosumers. IEEE Trans. Ind. Inform. 2019, 15, 2523-2534. [CrossRef]

45. Morstyn, T.; McCulloch, M.D. Multiclass Energy Management for Peer-to-Peer Energy Trading Driven by Prosumer Preferences. IEEE Trans. Power Syst. 2019, 34, 4005-4014. [CrossRef]

46. Mahmood, A.; Butt, A.R.; Mussadiq, U.; Nawaz, R.; Zafar, R.; Razzaq, S. Energy sharing and management for prosumers in smart grid with integration of storage system. In Proceedings of the 2017 5th International Istanbul Smart Grid and Cities Congress and Fair (ICSG), Istanbul, Turkey, 19-21 April 2017; pp. 153-156. [CrossRef]

47. Rathnayaka, A.J.D.; Potdar, V.M.; Hussain, O.; Dillon, T. Identifying prosumer's energy sharing behaviours for forming optimal prosumer-communities. In Proceedings of the 2011 International Conference on Cloud and Service Computing, Hong Kong, China, 12-14 December 2011; pp. 199-206. [CrossRef]

48. Rathnayaka, A.J.D.; Potdar, V.M.; Dillon, T.S.; Hussain, O.K.; Chang, E. A methodology to find influential prosumers in prosumer community groups. IEEE Trans. Ind. Inform. 2014, 10, 706-713. [CrossRef] 
49. Leal-Arcas, R.; Lesniewska, F.; Proedrou, F. Prosumers: New Actors in EU Energy Security. In Netherlands Yearbook of International Law 2017; T.M.C. Asser Press: The Hague, The Netherlands, 2018; ISBN 9789462652439. [CrossRef]

50. Gowida, A.; Moussa, T.; Elkatatny, S.; Ali, A. A hybrid artificial intelligence model to predict the elastic behavior of sandstone rocks. Sustainability 2019, 11, 5283. [CrossRef]

51. Kancelaria Sejmu, R.P. Ustawa O Odnawialnych Źródtach Energii (Renewable Energy Sources Act) Dz. U. 2015 poz. 478 ; 2015. Available online: https:/ / isap.sejm.gov.pl/isap.nsf/DocDetails.xsp?id=wdu20150000478 (accessed on 12 January 2021).

52. Thankachen, P.; Thomas, D.A. Hysteresis controller based fault current interruption using DVR. In Proceedings of the 2014 Annual International Conference on Emerging Research Areas: Magnetics, Machines and Drives (AICERA/iCMMD), Kottayam, India, 24-26 July 2014; pp. 1-4. [CrossRef]

53. Jena, S.; Babu, B.C.; Naik, A.K.; Mishra, G. Performance improvement of single-phase grid - Connected PWM inverter using PI with hysteresis current controller. In Proceedings of the 2011 International Conference on Energy, Automation and Signal, Bhubaneswar, India, 28-30 December 2011; pp. 176-180. [CrossRef]

54. PGE Dystrybucja, S.A. Instrukcja Ruchu i Eksploatacji Sieci Przesyłowej (Instruction of the Transmission Network Operation and Maintenance). 2013. Available online: https://pgedystrybucja.pl/o-spolce/dzialalnosc/iriesd (accessed on 12 January 2021). 